\title{
Body mass index, Bishop score, and sonographic measurement of the cervical length as predictors of successful labor induction in twin gestations
}

\author{
Kyo-Hoon Park*, Joon-Seok Hong, Woong-Sun \\ Kang, Dong-Myung Shin and Shi-Nae Kim \\ Departments of Obstetrics and Gynecology, Seoul \\ National University College of Medicine, Seoul National \\ University Bundang Hospital, Seongnamsi, Korea
}

\begin{abstract}
Aims: To evaluate the predictive value of body mass index (BMI), Bishop score, and sonographic measurement of cervical length for predicting successful labor induction (defined as an ability to achieve the active phase of labor corresponding to a cervical dilatation of $\geq 4 \mathrm{~cm}$ within $12 \mathrm{~h}$ of initiating oxytocin) in near-term twin gestations.
\end{abstract}

Methods: This prospective, observational study enrolled 72 consecutive women with twin gestations at $>36.0$ weeks' gestation who were scheduled for induction of labor. Transvaginal ultrasound for measurement of the cervical length was performed and the Bishop score was determined by digital examination. The BMI was calculated based on the weight and height at the time of induction.

Results: Labor induction was successful in 63\% (45/72) of women. The mean BMI was significantly lower in women who had successfully induced labor, but no significant differences existed with respect to the mean cervical length, median Bishop score, proportion of parous and nulliparous women, and the mean total birth weight of the twin pairs between the two patient groups. Multiple logistic regression demonstrated that only BMI provided a significant contribution in predicting successful labor induction.

Conclusions: BMI independently predicted the success of labor induction in twin gestations but the sonographic

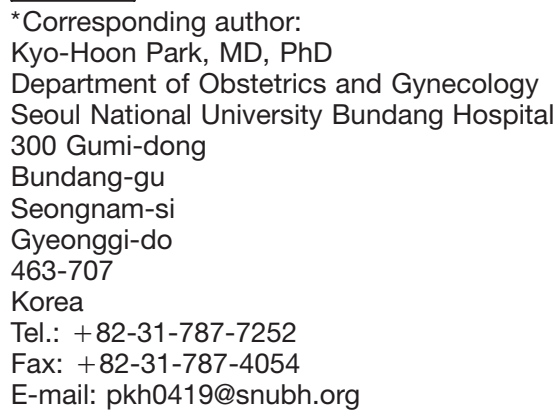

measurement of the cervical length and Bishop score had poor predictive values for successful induction.

Keywords: Bishop score; body mass index; cervical length; labor induction; twin gestations.

\section{Introduction}

Twin pregnancies comprise 2-3\% of all live births [9] and are associated with an increased risk of obstetric complications, such as preeclampsia, gestational diabetes, fetal growth restriction, or growth discordance [1, 18, 20]. In twins, these obstetric complications may frequently necessitate induction of labor. However, since there is little information regarding the clinical and ultrasonographic parameters which predict the success of labor induction in twin gestations, general predictors of the success or failure of labor induction based on data from singleton gestations are commonly used. Nevertheless, such an approach may be questionable because normal maternal physiologic changes (uterine volume, cervical length, and maternal weight gain) are different in twin gestations [1, 10].

The prelabor condition of the cervix is believed to be one of the most important predictors of successful induction [19, 22, 25]. Traditionally, assessment of the cervix prior to labor induction has been accomplished by using the Bishop score, which remains the current standard for predicting the outcome of labor induction. However, this assessment is somewhat subjective and has a high intra- and inter-observer variation. In contrast, transvaginal ultrasound assessment of the cervix is an objective and more reproducible method, and moreover, it allows visualization of the cervix beyond the closed external os. Importantly, a recent meta-analysis indicated that both transvaginal ultrasonographic measurement of the cervical length and the Bishop score predicted successful induction of labor, but the diagnostic accuracy of sonographically measured cervical length was not superior to that of the Bishop score [6]. However, the value of these parameters has been examined only in women with singleton gestations undergoing induction of labor. At present, there are no data about the predictive value of these parameters for successful labor induction in twin gestations.

As well as an assessment of the cervix, obesity, as reflected by an increased body mass index (BMI), has 
recently been implicated as one of the important potential parameters affecting outcome of labor induction because it may impair the ability of the uterus to contract in labor or necessitate a higher dose of oxytocin [16, $22,26]$. Excessive weight gain during pregnancy and increased maternal BMI near-term are encountered more frequently in twin than in singleton gestations [4, 17]. Therefore, it is possible that outcome of labor induction in twin gestations might be influenced by maternal BMI. The purpose of this study was to evaluate the predictive value of the BMI, Bishop score, and the sonographic measurement of the cervical length for predicting successful labor induction in twin gestations.

\section{Materials and methods}

This prospective study was conducted on women with twin gestations who were admitted for induction of labor to Seoul National University Bundang Hospital (Seongnamsi, Korea) between March 2004 and September 2008. The inclusion criteria were: (1) a viable twin gestation; (2) both fetuses in the vertex presentation; (3) > 36.0 weeks' gestation; (4) intact amniotic membranes; (5) absence of active labor; (6) no history of previous uterine surgery, and (7) no contraindication to vaginal delivery. This study was approved by the Institutional Review Board of the Seoul National University Bundang Hospital (Seongnamsi, Korea), and informed consent was obtained from all study subjects.

The BMI was calculated $\left(\mathrm{kg}\right.$ per $\left.\mathrm{m}^{2}\right)$ based on the weight and height at the time of induction. On admission to the labor and delivery floor, transvaginal ultrasonographic assessment of the cervical length was performed by one of the authors (K.H.P.) using an Envisor (Philips Medical System, Eindhoven, The Netherlands) ultrasound machine with a $6.0 \mathrm{MHz}$ transducer. The method used for measurement of the cervical length was previously described [11]. Three measurements were performed and the shortest distance was taken as the cervical length. The Bishop score was determined [2] by the resident physician responsible for the induction of labor; the resident physician was blinded to the sonographic cervical findings.

Induction of labor was carried out according to the standard labor induction protocol used at the Seoul National University Bundang Hospital. External cardiotocography was performed to assess fetal well-being, as well as to confirm the absence of contraction. If the Bishop score was $\leq 5$, a 10 -mg dinoprostone vaginal insert (Propess; Ferring Pharmaceuticals, Malmo, Sweden) was placed transversely in the posterior fornix of the vagina at 9:00 pm to initiate cervical ripening before labor induction. After $9 \mathrm{~h}$, i.e., 6:00 am the following day, the dinoprostone vaginal insert was removed and an intravenous oxytocin infusion was started if regular uterine contractions and cervical change did not develop. Oxytocin was administered intravenously as a dilute solution using a constant infusion pump. The initial dose was set at $5.3 \mathrm{mU} / \mathrm{min}$ and this was increased by one-half of the previous infusion rate every $30 \mathrm{~min}$ up to a maximum dose of $40 \mathrm{mU} / \mathrm{min}$ until regular painful uterine contractions ensued or labor progressed. The oxytocin infusion was continued for at least $12 \mathrm{~h}$. In patients who had not gone into active labor during this $12 \mathrm{~h}$ period, labor was induced by repeating the same pro- tocol (i.e., a serial induction was performed). Fetal heart rates were monitored using a continuous electronic system in all patients. Amniotomy was not performed until the cervix became dilated to at least $3 \mathrm{~cm}$ and the vertex was engaged.

Successful labor induction was defined as an ability to achieve the active phase of labor, corresponding to a cervical dilatation of $\geq 4 \mathrm{~cm}$ within $12 \mathrm{~h}$ of initiating oxytocin (i.e., within $21 \mathrm{~h}$ of the insertion of a dinoprostone vaginal insert).

Univariate analysis was conducted with the Student's $t$-test, Mann-Whitney $U$-test, $\chi^{2}$-test or Fisher's exact test. Variables found to have a significant correlation or a tendency toward an association with successful labor induction in univariate analysis $(P<0.25)$ were entered into a logistic regression model in order to select independent predictors in the success of induction. In the logistic regression model, all factors were entered as dichotomous variables and the receiver operating characteristic $(\mathrm{ROC})$ curves were used to identify the best cut-off values for dichotomization. The ROC curve was constructed to describe the relationship between the sensitivity (true-positive rate) and the false-positive rate for BMI in the prediction of successful labor induction. Using an $\alpha$ of 0.05 and a power of 0.8 , and assuming a ratio of 3:2 for the success to failure of labor induction among study groups, we calculated that a sample of 68 women would be needed to detect a $5 \mathrm{~mm}$ difference in cervical length with a standard deviation of $7 \mathrm{~mm}$ (based on a pilot study). $\mathrm{P}<0.05$ were considered statistically significant. SPSS 12.0.1 (Chicago, IL, USA) was used for statistical analyses.

\section{Results}

Seventy-two consecutive women were enrolled during the study period. The indications for labor induction were as follows: prolonged pregnancy of 38 completed weeks or greater $(n=42)$; suspected fetal growth restriction or growth discordance $(n=11)$; preeclampsia $(n=7)$; oligohydramnios $(n=4)$; gestational diabetes $(n=3)$; non-reassuring non-stress test $(n=2)$, and chronic hypertension $(n=3)$. No women declined to participate in this study.

A twin vaginal delivery occurred in $49(68 \%)$ women and $40(82 \%)$ of these deliveries occurred within $24 \mathrm{~h}$ of induction. Cesarean delivery for both twins was performed in 21 (29\%) women because of failure to progress $(n=10)$, induction failure $(n=1)$, suspected fetal distress $(n=1)$, and maternal request for social reasons or discomfort $(n=9)$. Combined vaginal-cesarean delivery of twins was performed in two women because of arrest of descent $(n=1)$ and suspected fetal distress in the second twin $(n=1)$. Of 45 women who delivered within $24 \mathrm{~h}$ of induction, there were five cesarean deliveries for failure to progress, and of 27 women who delivered after $24 \mathrm{~h}$, there were 16 cesarean deliveries and two combined vaginal-cesarean deliveries. With respect to the method of induction, 53 patients received both prostaglandin and oxytocin; 17 patients received oxytocin only and two patients were delivered after prostaglandin administration only.

Table 1 lists the clinical characteristics and obstetric outcomes of patients according to the success or failure 
Table 1 The clinical characteristics of the study population.

\begin{tabular}{|c|c|c|c|}
\hline \multirow[t]{2}{*}{ Characteristics } & \multicolumn{2}{|l|}{ Induction of labor } & \multirow[t]{2}{*}{ P-values } \\
\hline & Success $(n=45)$ & Failure $(n=27)$ & \\
\hline Maternal age (years) & $31.2 \pm 3.1$ & $30.4 \pm 3.4$ & 0.430 \\
\hline Maternal BMI (kg/m²) & $27.4 \pm 2.4$ & $29.5 \pm 3.2$ & 0.001 \\
\hline Nulliparity & $82 \%(37 / 45)$ & $85 \%(23 / 27)$ & 1.000 \\
\hline Gestational age at induction (weeks) & $37.6 \pm 0.8$ & $37.4 \pm 1.0$ & 0.302 \\
\hline Bishop score at induction & $4(0-8)$ & $3(0-7)$ & 0.325 \\
\hline Cervical length by ultrasound (mm) & $18.5 \pm 6.6$ & $21.6 \pm 9.4$ & 0.217 \\
\hline \multicolumn{4}{|l|}{ Indication for induction of labor } \\
\hline Prolonged pregnancy & $60 \%(27 / 45)$ & $56 \%(15 / 27)$ & \\
\hline Preeclampsia & $9 \%(4 / 45)$ & $11 \%(3 / 27)$ & \\
\hline Others & $31 \%(14 / 45)$ & $33 \%(9 / 27)$ & \\
\hline Use of prostaglandin & $69 \%(31 / 45)$ & $78 \%(21 / 27)$ & 0.588 \\
\hline Sum of the birth weights of the twin pairs (g) & $5194 \pm 588$ & $5421 \pm 600$ & 0.130 \\
\hline Cesarean delivery for both twins & $11 \%(5 / 45)$ & $59 \%(16 / 27)$ & $<0.001$ \\
\hline
\end{tabular}

Values are given as the mean $\pm \mathrm{SD}$, median (range) or $\%$ (n). BMI = body mass index.

of labor induction. Labor induction was successful in $63 \%(45 / 72)$ of the cases, and 27 women failed to enter the active phase of labor within $24 \mathrm{~h}$ of induction. No significant differences were found in terms of the mean maternal age, the distribution of parous and nulliparous women, the prevalence of prostaglandin use, and the mean total birth weights of the twin pairs between the two groups. Moreover, the mean cervical length measured sonographically and the median Bishop score were not significantly different between the two patients groups. However, women who had successful labor induction had a significantly lower mean BMI than those who failed to induce labor.

Multiple logistic regression analysis was performed using BMI ( $<30$ vs. $\geq 30 \mathrm{~kg} / \mathrm{m}^{2}$ ), sonographic cervical length ( $<20 \mathrm{~mm}$ vs. $\geq 20 \mathrm{~mm}$ ), and total birth weights of the twin pairs ( $<5400 \mathrm{~g}$ vs. $\geq 5400 \mathrm{~g}$ ) as independent variables. Of these independent variables, only BMI significantly and independently contributed to the success of labor induction (Table 2). The difference remained statistically significant in both univariate and multivariate

Table 2 Logistic regression analysis of independent variables in predicting the success of labor induction.

\begin{tabular}{lllr}
\hline & $\begin{array}{l}\text { Odds } \\
\text { ratio }\end{array}$ & $\begin{array}{l}95 \% \\
\text { Confidence } \\
\text { interval }\end{array}$ & P-values \\
\hline Higher body mass & & & \\
index & 0.070 & $0.017-0.294$ & $<0.001$ \\
$\begin{array}{l}\text { Short cervix } \\
\text { Higher sum of the birth }\end{array}$ & 1.867 & $0.588-5.930$ & 0.289 \\
$\begin{array}{l}\text { weight of the twin } \\
\text { pairs* }\end{array}$ & & $0.180-1.854$ & 0.356 \\
\hline
\end{tabular}

*Variables were dichotomized: higher body mass index $(<30 \mathrm{~kg} /$ $\mathrm{m}^{2}$ vs. $\left.\geq 30 \mathrm{~kg} / \mathrm{m}^{2}\right)$, short cervix $(<20 \mathrm{~mm}$ vs. $\geq 20 \mathrm{~mm})$, and higher sum of the birth weights of the twin pairs $(<5400 \mathrm{~g}$ vs. $\geq 5400 \mathrm{~g}$ ). analyses when all patients with preeclampsia were removed from the dataset.

The ROC curve constructed to determine the best cutoff value of the BMI to predict successful labor induction is presented in Figure 1. The curve constructed for the $\mathrm{BMI}$ was above the $45^{\circ}$ line, indicating a significant relationship between this variable and successful induction (area under the curve 0.728; SE 0.066; $P=0.001$ ). The best cut-off value for predicting successful labor induction was $30 \mathrm{~kg} / \mathrm{m}^{2}$, with a sensitivity of $93 \%(42 / 45)$, a specificity of $52 \%(14 / 27)$, and positive and negative predictive values of $76 \%(42 / 55)$ and $82 \%$ (14/17), respectively.

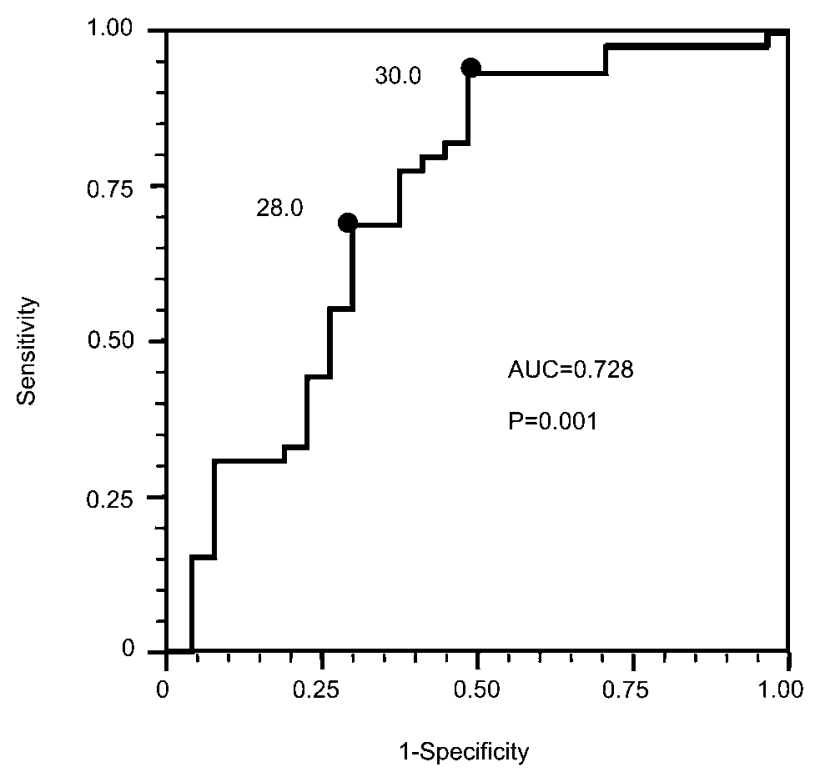

Figure 1 Receiver operating characteristic curve for the body mass index (BMI) at the time of induction to predict success of labor induction. The number next to the solid dot represents the $\mathrm{BMI}$ (area under the curve 0.728; SE 0.066; $\mathrm{P}=0.001$ ). 


\section{Discussion}

This is the first study to examine the predictive value of the Bishop score and the sonographic measurement of the cervical length for predicting successful labor induction in twin gestations. The results were unexpected in that both the sonographic measurement of the cervical length and the Bishop score had a poor predictive value for the likelihood of successful induction. Furthermore, logistic regression analysis indicated that only BMI was an independent predictor of successful labor induction in twin gestations.

Based on studies of predictors of successful labor induction in singleton gestations indicate that clinical or ultrasonographic cervical parameters are the strongest determinants of successful labor induction, whereas maternal body weight or BMI plays a less significant role $[8,11,13]$. However, our study demonstrated that in twin gestations, only BMI significantly and independently predicted the success of labor induction. Moreover, this finding cannot be explained by its association with birth weight because when the total birth weights of the twin pairs was entered into the logistic regression model, the BMI remained significant. These observations might have clinical importance since accurate information about failed induction in twin gestations should be given on the basis of the BMI, but not cervical parameters. Simply put, women with a BMI $\geq 30 \mathrm{~kg} / \mathrm{m}^{2}$ have an $82 \%$ chance of remaining undelivered within $24 \mathrm{~h}$ of induction, whereas those with a BMI $<30 \mathrm{~kg} / \mathrm{m}^{2}$ can be advised about a $76 \%$ chance of delivering within this interval.

The association between the sonographic cervical length and successful labor induction in singleton gestations has been the subject of intense investigation [6]. However, some studies have found the sonographic assessment of the cervical length predictive of induction success [11, 13, 23, 24], whereas other studies have not found such an association $[5,14,15]$. The disparity among these studies is probably attributable, in part, to a variety of primary outcome variables, including vaginal delivery, vaginal delivery within $24 \mathrm{~h}$ of initiation of induction, and reaching the active phase of labor as the definition of induction success. Nevertheless, reaching the active phase of labor may be a more appropriate outcome variable because it is unreasonable to classify the cases of patients who required cesarean delivery for nonreassuring fetal heart rate tracings and arrest disorders during the active phase and second stage of labor as induction failures. In recent studies of singleton pregnancies, Park [11] and Yang et al. [24] used this outcome to define induction success and consistently showed that the sonographic measurement of the cervical length independently predicted successful labor induction. These findings are in contrast with our study. The discrepant results between these studies may reflect differences of biological responses between singleton and twin gestations. Alternatively, if the intensity of uterine contractions, which exert hydrostatic pressure through the fetal membranes against the cervix and in turn dilate the cervical canal like a wedge, is the same between singleton and twin gestations, during a contraction the pressure exerted against the cervix is relatively low in the case of gestations with an increased uterine volume, such as a twin gestation. Perhaps this is probably why cervical parameters in twin gestations are not useful in predicting induction success.

This study demonstrated that in twin gestations undergoing induction of labor with oxytocin and prostaglandin $E_{2}$ at $>36.0$ weeks' gestation, successful vaginal delivery occurred within $24 \mathrm{~h}$ of induction in 56\% (40/72) of the women. This finding is compatible with the results reported in singleton gestations [11, 13] and suggest that induction of labor in twin gestations with oxytocin and prostaglandin $\mathrm{E}_{2}$ appears to be effective in achieving vaginal delivery. Indeed, labor induction in advanced twin gestations is a cause for clinical concern because an over distended uterus might be resistant to uterotonic drugs or, conversely, be prone to hyperstimulation or even uterine rupture with relatively low doses of uterotonic drugs. Although our study was not designed to address the overall effectiveness and safety of labor induction in twin gestations, there were no untoward events in both the mother and neonates, like the other studies in twin gestations $[3,21]$, with the incidence of cesarean delivery for non-reassuring fetal heart rate tracing $1 / 72$. However, it should be noted that a $10-\mathrm{mg}$ dinoprostone vaginal insert (Propess; Ferring) for cervical ripening and labor induction used in this study is not licensed for use in twin pregnancies and any recommendations for the use in twin pregnancies in clinical practice should be discussed considering this fact.

We acknowledge that our study was limited by its relatively small sample size and the inclusion of a heterogeneous group of patients regarding the indication for medical induction at different gestational ages (e.g., preeclampsia and prolonged pregnancy). Indeed, women with preeclampsia had a higher weight or BMI compared with those with uncomplicated pregnancies [12] and with increasing gestational age during the third trimester, there was an increase in the BMl and the cervical ripening [4, 7]. Therefore, the BMI, Bishop score and the sonographic cervical length might be different according to indication or gestational age. However, we believe that our main results remain valid because these potential confounding variables were controlled in the regression model and exclusion of preeclamptic patients did not alter the results. Another limitation of the present study might be the induction regimen because this may influence the outcome of induction, and then the results of our study need to be replicated in other settings using other regimens. Because of these limitations, further large prospective studies with a larger number of patients are needed to confirm our observations. 
In conclusion, only the BMI independently predicted the success of labor induction in twin gestations. However, the sonographic measurement of the cervical length and the Bishop score appeared to have poor predictive values for successful induction.

\section{References}

[1] Ayres A, Johnson TR. Management of multiple pregnancy: prenatal care - part II. Obstet Gynecol Surv. 2005;60: 538-49.

[2] Bishop EH. Pelvic scoring for elective induction. Obstet Gynecol. 1964;24:266-8.

[3] Bush MC, Csaba A, Eddleman KA, Saphier CJ. Is misoprostol safe for labor induction in twin gestations? J Matern Fetal Neonatal Med. 2006;19:35-8.

[4] Campbell DM. Maternal adaptation in twin pregnancy. Semin Perinatol. 1986;10:14-8.

[5] Chandra S, Crane JM, Hutchens D, Young DC. Transvaginal ultrasound and digital examination in predicting successful labor induction. Obstet Gynecol. 2001;98:2-6.

[6] Crane JMG. Factors predicting labor induction: a critical analysis. Clin Obstet Gynecol. 2006;49:573-84.

[7] Fujita MM, Brizot Mde L, Liao AW, Bernáth T, Cury L, Neto $\mathrm{JD}$, et al. Reference range for cervical length in twin pregnancies. Acta Obstet Gynecol Scand. 2002;81:856-9.

[8] Grobman WA, Simon C. Factors associated with the length of the latent phase during labor induction. Eur $\mathrm{J}$ Obstet Gynecol Reprod Biol. 2007;132:163-6.

[9] MacDorman MF, Minino AM, Strobino DM, Guyer B. Annual summary of vital statistics-2001. Pediatrics. 2002; 110:1037-52.

[10] Meath AJ, Ramsey PS, Mulholland TA, Rosenquist RG, Lesnick T, Ramin KD. Comparative longitudinal study of cervical length and induced shortening changes among singleton, twin, and triplet pregnancies. Am J Obstet Gynecol. 2005;192:1410-5.

[11] Park KH. Transvaginal ultrasonographic cervical measurement in predicting failed labor induction and cesarean delivery for failure to progress in nulliparous women. $\mathrm{J}$ Korean Med Sci. 2007;22:722-7.

[12] Park KH, Cho YK, Lee CM, Choi H, Kim BR, Lee HK. Effect of preeclampsia, magnesium sulfate prophylaxis, and maternal weight on labor induction: a retrospective analysis. Gynecol Obstet Invest. 2006;61:40-4.

[13] Rane SM, Guirgis RR, Higgins B, Nicolaides KH. Models for the prediction of successful induction of labor based on pre-induction sonographic measurement of cervical length. J Matern Fetal Neonatal Med. 2005;17:315-22.

[14] Reis FM, Gervasi MT, Florio P, Bracalente G, Fadalti M, Severi FM, et al. Prediction of successful induction of labor at term: role of clinical history, digital examination, ultrasound assessment of the cervix, and fetal fibronectin assay. Am J Obstet Gynecol. 2003;189:1361-7.

[15] Roman H, Verspyck E, Vercoustre L, Degre S, Col JY, Firmin JM, et al. Does ultrasound examination when the cervix is unfavorable improve the prediction of failed labor induction? Ultrasound Obstet Gynecol. 2004;23:357-62.

[16] Satin AJ, Leveno KJ, Sherman ML, Mclntire DD. Factors affecting the dose response to oxytocin for labor stimulation. Am J Obstet Gynecol. 1992;166:1260-1.

[17] Schiff E, Cohen SB, Dulitzky M, Novikov I, Friedman SA, Mashiach S, et al. Progression of labor in twin versus singleton gestations. Am J Obstet Gynecol. 1998;179: 1181-5.

[18] Schwartz DB, Daoud Y, Zazula P, Goyert G, Bronsteen R, Wright D, et al. Gestational diabetes mellitus: metabolic and blood glucose parameters in singleton versus twin pregnancies. Am J Obstet Gynecol. 1999;181:912-4.

[19] Seyb ST, Berka RJ, Socol ML, Dooley SL. Risk of cesarean delivery with elective induction of labor at term in nulliparous women. Obstet Gynecol. 1999;94:600-7.

[20] Sibai BM, Hauth J, Caritis S, Lindheimer MD, MacPherson $\mathrm{C}$, Klebanoff $\mathrm{M}$, et al. Hypertensive disorders in twin versus singleton gestations. National Institute of Child Health and Human Development Network of Maternal-Fetal Medicine Units. Am J Obstet Gynecol. 2000;182:938-42.

[21] Simões T, Condeço P, Dias E, Ventura P, Matos C, Blickstein I. Induction of labor with oral misoprostol in nulliparous mothers of twins. J Perinat Med. 2006;34:111-4.

[22] Vrouenraets FP, Roumen FJ, Dehing CJ, van den Akker ES, Aarts MJ, Scheve EJ. Bishop score and risk of cesarean delivery after induction of labor in nulliparous women. Obstet Gynecol. 2005;105:690-7.

[23] Ware V, Raynor BD. Transvaginal ultrasonographic cervical measurement as a predictor of successful labor induction. Am J Obstet Gynecol. 2000;182:1030-2.

[24] Yang SH, Roh CR, Kim JH. Transvaginal ultrasonography for cervical assessment before induction of labor. J Ultrasound Med. 2004;23:375-82.

[25] Yeast JD, Jones A, Poskin M. Induction of labor and the relationship to cesarean delivery: a review of 7001 consecutive inductions. Am J Obstet Gynecol. 1999;180:62833.

[26] Zhang J, Bricker L, Wray S, Quenby S. Poor uterine contractility in obese women. Br J Obstet Gynaecol. 2007;114: 343-8.

The authors stated that there are no conflicts of interest regarding the publication of this article.

Received October 31, 2008. Revised March 11, 2009. Accepted March 26, 2009. Previously published online June 3, 2009. 